21 Rolfe S, Harper NJN. Ability of hospital doctors to calculate drug doses. BMJ 1995;310:1173-4

22 Stoneham M, Saville GM, Wilson IH. Knowledge about pulse oximetry among medical and nursing staff. Lancet 1994;344:1339-42.

23 Montgomery H, Hunter S, Morris S, Naunton-Morgan R, Marshall RM. Interpretation of electocardiograms by doctors. BMJ 1994;309:1551-2.

24 Gould TH, Upton PM, Collins P. A survey of the intended management of acute postoperative pain by newly qualified doctors in the South West region of England. Anaesthesia 1994;49:807-10.

25 Report of the working party on the management of patients with major injuries. Royal College of Surgeons of England, 1985.

26 Allan A, McQuillan PJ, Taylor BL, Nielsen MS, Collins CH, Short AIK, et al. Who sees the critically ill patient before ICU admission? Clin Intensive Care 1994;5:152.

27 Mather HM, Elkeles RS. Attitudes of consultant physicians to the Calman proposals: a questionnaire survey. BMJ 1995;311:1060-2.

28 Sax FL, Charlson ME. Medical patients at high risk for catastrophic deterioration. Crit Care Med 1987;15:510-5.

29 Franklin C, Mathew J. Developing strategies to prevent inhospital cardiac arrest: analyzing responses of physicians and nurses in the hours before the event. Crit Care Med 1994;22:244-7.

30 Schein RMH, Hazday N, Pena M, Ruben BH, Sprung CL. Clinical antecedents to in-hospital cardiopulmonary arrest. Chest 1990;98:1388-92.

31 Bedell SE. Incidence and characteristics of preventable iatrogenic cardiac arrest. JAMA 1991;265:2815-20.
32 Dubois RW. Preventable deaths; who, how often and why? Ann Int Med 1988;109:582-9.

33 George Jr AL. Prearrest morbidity and other correlates of survival after in hospital cardiac arrest. Am J Med 1989;87:28-34.

34 Lee A, Bishop G, Hillman KM, Daffurn K. The medical emergency team. Anaesth Intensive Care 1995;23:183-6.

35 Daffurn K, Lee A, Hillman KM, Bishop GF, Bauman A. Do nurses know when to summon emergency assistance? Intensive Crit Care Nurs 1994; 10:115-20

36 Hournihan F, Bishop G, Hillman KM, Daffurn K, Lee A. The medical emergency team: a new strategy to identify and intervene in high-risk surgical patients. Clin Intensive Care 1995;6:269-72.

37 Capewell S. The continuing rise in emergency admissions. BMJ 1996;312:991-2.

38 Moss F, McNicol M. Alternative models of organisation are needed. BMJ 1995;310:925-8

39 Smith J. Consultants of the future. BMJ 1995;310:953-4.

40 Delamothe A. Wanted: guidelines that doctors will follow. BMJ 1993;307:218.

41 Royal College of Physicians of London. Future patterns of care by general and specialist physicians. London: RCP, Sept 1996.

42 Pope A. The penguin dictionary of quotations. In:JM Cohen and MJ Cohen, eds. Hertfordshire, Omega, 1960

(Accepted 12 August 1997)

\title{
Hormone replacement therapy and risk of hip fracture: population based case-control study
}

\author{
Karl Michaëlsson, John A Baron, Bahman Y Farahmand, Olof Johnell, Cecilia Magnusson, \\ Per-Gunnar Persson, Ingemar Persson, Sverker Ljunghall on behalf of the Swedish Hip Fracture \\ Study Group
}

Editorial by Khaw
Department of
Orthopaedics,
University Hospital,
S-751 85 Uppsala,
Sweden
Karl Michaëlsson
senior registrar
Departments of
Medicine and
Community and
Family Medicine,
Dartmouth Medical
School, Hanover,
New Hampshire,
USA
John A Baron
professor
Department of
Medical
Epidemiology,
Karolinska Institute
Box 281, S-171 77
Stockholm, Sweden
Cecilia Magnusson
research fellow
Ingemar Persson
reader
Department of
Epidemiology,
Stockholm County
Council, 171 76
Stockholm, Sweden
Bahman Y
Farahmand
statistician
Per-Gunnar Persson
reader
continued over

BMJ 1998;316:1858-63

\begin{abstract}
Objective: To determine the relative risk of hip fracture associated with postmenopausal hormone replacement therapy including the effect of duration and recency of treatment, the addition of progestins, route of administration, and dose.

Design: Population based case-control study. Setting: Six counties in Sweden.

Subjects: 1327 women aged 50-81 years with hip fracture and 3262 randomly selected controls.

Main outcome measure: Use of hormone replacement therapy.

Results: Compared with women who had never used hormone replacement therapy, current users had an odds ratio of 0.35 (95\% confidence interval 0.24 to 0.53 ) for hip fracture and former users had an odds ratio of 0.76 ( 0.57 to 1.01$)$. For every year of therapy, the overall risk decreased by $6 \%$ (3\% to $9 \%)$ : $4 \%$ ( $1 \%$ to $8 \%)$ for regimens without progestin and $11 \%(6 \%$ to $16 \%$ ) for those with progestin. Last use between one and five years previously, with a duration of use more than five years, was associated with an odds ratio of 0.27 (0.08 to 0.94$)$. After five years without hormone replacement therapy the protective effect was substantially diminished ( $-7 \%$ to $48 \%$ ). With current use, an initiation of therapy nine or more years after the menopause gave equally strong reduction in risk for hip fracture as an earlier start. Oestrogen treatment with skin patches gave similar risk estimates as oral regimens.

Conclusions: Recent use of hormone replacement therapy is required for optimum fracture protection, but therapy can be started several years after the menopause. The protective effect increases with duration of use, and an oestrogen-sparing effect is achieved when progestins are included in the regimen.
\end{abstract}

\section{Introduction}

Menopause is accompanied by accelerated bone $\operatorname{loss}^{12}$ and by an increase in the incidence of fractures such as those of the hip. ${ }^{34}$ Many studies have shown that hormone replacement therapy can reduce bone loss ${ }^{56}$ and the risk of hip fracture. ${ }^{7}$ However, the dose and duration of treatment needed, the duration of the protective effect after treatment is stopped, the influence of age at which treatment is initiated, and the efficacy of different hormone replacement therapy regimens remain unclear. We carried out a large, population based, case-control study to evaluate these issues.

\section{Subjects and methods}

The study was conducted in the Swedish counties of Stockholm, Uppsala, Västmanland, Örebro, Göteborg, and Malmöhus. This largely urban area in the middle, west, and south of Sweden includes nearly half of the 8.6 million inhabitants of Sweden.

\section{Cases}

We aimed to ascertain all cervical, pertrochanteric, or subtrochanteric fractures of the proximal femur among women resident in the study area who were born in 1914 or after and treated during October 1993 to February 1995. Using hospital discharge records or operation registers in all 24 hospitals in the study area we identified 2597 possible incident cases. We excluded those with a fracture due to malignancy $(n=26)$, high energy trauma $(n=4)$, incorrect diagnosis $(n=41)$, old fracture $(n=10)$, blindness $(n=5)$, birth outside of Sweden $(n=202)$, a diagnosis of severe alcohol misuse, psychosis, or senile dementia $(n=576)$ or death within three months of the fracture $(n=123)$. All hospital records were scrutinised to confirm eligibility and to ascertain type of hip fracture and previous hip fracture. 
There remained 1610 eligible cases. We sent these women a comprehensive questionnaire at a mean interval of 95 days (SD 23 days) after the fracture. At the end of the study the Swedish inpatient register identified 34 additional cases, who were also asked to complete the questionnaire.

\section{Controls}

The controls were women born in Sweden randomly selected from the national, continuously updated population register. The selection was made the month before the start of the study. Questionnaires were sent to controls on six occasions evenly distributed through the study period. Potential controls aged 70-80 years were frequency matched (two controls: one case) to the expected age distribution of hip fracture within county of residence. Controls aged 50-69 years were also residents of the study area randomly selected from the population register. These subjects were also possible controls for a breast cancer study being conducted at the same time with the same questionnaire to coordinate research efforts. The frequency matching to the expected number of breast cancer cases provided numbers sufficient for two to four times as many controls as hip fracture cases in each five year age group and county of residence. Of all the 4872 candidate controls in the hip fracture analysis, 4059 were eligible, 610 were born outside of Sweden, 157 died before being approached, 44 had senility or psychosis, and two were blind.

\section{Data collection}

We collected data through a postal questionnaire focusing on reproductive history and use of exogenous sex hormones, including oral contraceptives and hormone replacement therapy. Information requested included the doses and types of preparations, reason for treatment, and the duration and dates of exposure. Identification of treatments was aided by a picture chart of all preparations commonly used in Sweden during 1950-95. We also requested information on current weight and height, education, dietary habits, alcohol consumption, cigarette smoking, and physical activity (childhood, aged 18 to 30 , and recent years). About half of the participants were approached by telephone to obtain missing information.

Of those eligible, 1328 cases $(82.5 \%)$ and 3312 controls $(81.6 \%)$ answered the questionnaire; of these, $202(15.2 \%)$ of the cases and $497(15.0 \%)$ of the controls responded solely by telephone in a less extensive interview. Participants claiming natural menses were classified as premenopausal (50 controls and one case) and were excluded from the analysis.

\section{Data analysis}

Hormone replacement therapy preparations were categorised as low potency oestrogens, mainly oestriol, progestins alone, unknown oestrogen preparations with or without progestins, "medium potency" oestrogens such as oestradiol and conjugated oestrogens given without progestins, and medium potency oestrogens combined with progestins. Only the two last groups were included in this analysis. The oestrogen only and oestrogen plus progestin regimens were further subdivided according to oestrogen dose. Low dose was $1 \mathrm{mg}$ of oestradiol, $0.325 \mathrm{mg}$ conjugated oestrogens, $5 \mu \mathrm{g}$ ethinyl oestradiol, or $25 \mu \mathrm{g}$ transdermal oestradiol per day; higher amounts were classed as high dose. Current use was defined as ongoing treatment at the time of fracture in cases and 95 days before the first questionnaire was sent in controls (the index dates). Former use was defined as discontinuation before the index date. Total duration of hormone replacement therapy, which excluded gaps in treatment, was considered in continuous form since we found a linear association with risk of hip fracture. Time since last use and since menopause were examined in three classes (12 months, 13-60 months, and $>60$ months for last use and 2 years, 3-8 years, or $\geqslant 9$ years for menopause).

Smoking status was defined as never, former, or current smoking at the index date. Reports of estimated leisure physical activity on a four point scale in each of the three periods were summed and condensed into a dichotomous variable as above or below the median for the controls. Body mass index was calculated as weight $(\mathrm{kg})$ one year before completing the questionnaire divided by the square of height $\left(\mathrm{m}^{2}\right)$ and categorised into quartiles. Age was considered in six classes: 50-54, 55-59, 60-64, 65-69, 70-74, and $75-81$ years. Age at menopause was defined as the age at the last menstrual period or age at bilateral oophorectomy if it was one year or more before data collection. If it was more recent women were considered premenopausal. Women who had had a hysterectomy, who had menses due to hormone replacement therapy, or who had missing information were considered postmenopausal if they had reached the age when natural menopause had occurred in 90\% of women ( 53 years in current smokers and 55 years in non-smokers) and otherwise as unknown. These subjects were assigned an age at menopause (by smoking status) corresponding to the mean age at natural menopause in our data. Menopausal age was then used as a three level variable ( -45 years, $46-54$ and $\geqslant 55$ ). Vasomotor symptoms at menopause were recorded as present or absent. Education was classified as primary school only versus a higher educational level.

We used odds ratios and 95\% confidence intervals computed by unconditional logistic regression as

Table 1 Characteristics of the participants and number of subjects providing information. Values are means (SD) unless indicated otherwise

\begin{tabular}{lccccc} 
& \multicolumn{2}{c}{ Cases } & & \multicolumn{2}{c}{ Controls } \\
\cline { 2 - 3 } Characteristic & $\begin{array}{c}\text { No (\%) } \\
\text { responding }\end{array}$ & Mean (SD) & & $\begin{array}{c}\text { No (\%) } \\
\text { responding }\end{array}$ & Mean (SD) \\
\hline Age (years) & 1327 & $72.5(6.8)$ & & 3262 & $70.5(7.7)$ \\
\hline Age at menopause (years) & 1327 & $50.0(4.4)$ & 3262 & $49.8(4.2)$ \\
\hline Age at menarche (years) & 948 & $13.8(1.5)$ & 2618 & $13.6(1.5)$ \\
\hline Weight (kg) & 1308 & $61.0(11.1)$ & 3233 & $66.8(11.8)$ \\
\hline Height (m) & 1307 & $1.64(0.07)$ & 3235 & $1.63(0.06)$ \\
\hline Body mass index (kg/m $\left.{ }^{2}\right)$ & 1294 & $22.2(3.8)$ & 3216 & $24.6(4.2)$ \\
\hline No (\%) ever used postmenopausal oestrogen* & $371(28)$ & & $1189(36.5)$ & \\
\hline Mean duration of use of hormone replacement therapy among & ever users (months): & \\
\hline Any† & $120(9.0)$ & $60.5(73.3)$ & $456(14.0)$ & $67.5(79.9)$ \\
\hline Without progestins & $81(6.1)$ & $60.8(65.8)$ & $229(7.0)$ & $64.9(84.0)$ \\
\hline With progestins & $56(4.2)$ & $43.6(52.7)$ & $274(8.4)$ & $59.0(66.1)$ \\
\hline With progesterone-like progestins & $14(1.1)$ & $38.5(33.9)$ & $94(2.9)$ & $78.0(73.1)$ \\
\hline With testosterone-like progestins & $45(3.4)$ & $50.0(58.0)$ & $222(6.8)$ & $56.0(59.7)$ \\
\hline With cyclic progestins & $38(2.3)$ & $46.9(47.7)$ & $167(5.1)$ & $70.0(70.1)$ \\
\hline With continuous progestins & $23(1.7)$ & $45.7(60.3)$ & $138(4.2)$ & $64.3(61.2)$ \\
\hline
\end{tabular}

*Including oral or local treatment with oestriol or unspecified oestrogens.

†Medium potency oestrogens such as oestradiol compounds or conjugated oestrogens.
Department of
Orthopaedics, Hospital, S-205 02 Malmö, Sweden Olof Johnell professor

Department of Internal Medicine, University Hospital, S-751 85 Uppsala, Sweden

Sverker Ljunghall professor

Correspondence to: Dr Michaëlsson Karl.Michaelsson@ ortopedi.uu.se

Members of the study group are listed at the end of the paper. Malmö Genera 
Table 2 Odds ratios of hip fracture with use of hormone replacement therapy

\begin{tabular}{|c|c|c|c|c|c|c|}
\hline \multirow{2}{*}{$\begin{array}{l}\text { Use of hormone } \\
\text { replacement } \\
\text { therapy }\end{array}$} & \multicolumn{2}{|c|}{ Any } & \multicolumn{2}{|c|}{ Without progestin } & \multicolumn{2}{|c|}{ With progestin } \\
\hline & $\begin{array}{l}\text { No of cases/ } \\
\text { controls }\end{array}$ & $\begin{array}{c}\text { Odds ratio* } \\
(95 \% \mathrm{Cl})\end{array}$ & $\begin{array}{c}\text { No of cases/ } \\
\text { controls }\end{array}$ & $\begin{array}{l}\text { Odds ratio* } \\
(95 \% \mathrm{Cl})\end{array}$ & $\begin{array}{c}\text { No of cases/ } \\
\text { controls }\end{array}$ & $\begin{array}{c}\text { Odds ratio* } \\
(95 \% \mathrm{Cl})\end{array}$ \\
\hline Never & $956 / 2073$ & 1.00 (reference) & $956 / 2073$ & 1.00 (reference) & $956 / 2073$ & 1.00 (reference) \\
\hline Ever: & $120 / 456$ & 0.58 (0.46 to 0.75$)$ & $81 / 229$ & 0.69 (0.52 to 0.93$)$ & $56 / 274$ & $0.46(0.32$ to 0.66$)$ \\
\hline Current & $40 / 239$ & 0.36 (0.24 to 0.53$)$ & $16 / 62$ & 0.48 (0.26 to 0.87$)$ & $24 / 17$ & 0.29 (0.17 to 0.48$)$ \\
\hline Former & $80 / 217$ & 0.76 (0.57 to 1.01) & $65 / 167$ & 0.76 (0.56 to 1.04$)$ & $32 / 9$ & 0.71 (0.46 to 1.12$)$ \\
\hline \multicolumn{7}{|l|}{ Per year of use: } \\
\hline Ever & & 0.94 (0.91 to 0.97$)$ & & $0.96(0.92$ to 0.99$)$ & & $0.89(0.84$ to 0.94$)$ \\
\hline Current & & 0.91 (0.87 to 0.95$)$ & & 0.94 (0.88 to 0.99$)$ & & 0.84 (0.76 to 0.92$)$ \\
\hline Former & & 0.97 (0.93 to 1.02$)$ & & 0.98 (0.92 to 1.04$)$ & & 0.93 (0.85 to 1.02$)$ \\
\hline
\end{tabular}

${ }^{*}$ Adjusted for age (50 to 54,55 to 59,60 to 64,65 to 69,70 to 74,75 to 81 years) and the indication of hormone replacement therapy to prevent osteoporosis (yes/no).

measures of association. Adjustment for cigarette smoking, body mass index, leisure physical activity, education, age at menopause, climacteric symptoms, previous hip fracture, and county of residence influenced the odds ratios only marginally-that is, less than $10 \%$. Consequently, the analyses presented here were adjusted only for age and the indication of hormone replacement therapy to prevent osteoporosis, covariates which affected our odds ratios modestly.

\section{Results}

Table 1 summarises the characteristics of study participants. The hip fracture was cervical type in $817(61.6 \%)$ cases and trochanteric in $510(38.4 \%)$ cases. About $93 \%$ of the cases had their first hip fracture during the study period. Of those with an earlier fracture, $80 \%$ had had a cervical fracture.

Ever use of any hormone replacement therapy with medium potency oestrogens was associated with a substantial reduction in risk of fracture risk (table 2): odds ratio 0.58 (95\% confidence interval 0.46 to 0.75$)$. There was a $6 \%(3 \%$ to $9 \%)$ decrease in hip fracture risk for every year of use of hormone replacement therapy of any type. The odds ratio for current users was 0.36 (0.24 to 0.53$)$. Among current users of any type of hormone replacement therapy, the risk decreased by $9 \%$ (5\% to 13\%) per year. Combined oestrogen-progestin regimens conferred lower odds ratios than oestrogens alone. Among current users, each year of oestrogen use without progestin was associated with a $6 \%$ reduc- tion in risk ( $1 \%$ to $12 \%)$ compared with $16 \%$ ( $8 \%$ to $24 \%$ ) for combined treatment. The difference between oestrogen and oestrogen plus progestin treatment was less apparent among former users: the odds ratios per year of use were 0.98 (0.92 to 1.04) and 0.93 (0.85 to 1.02) respectively.

Compared with never users of hormone replacement therapy the odds of hip fracture was 0.27 ( 0.14 to 0.53 ) for current users of combined hormone replacement therapy with fewer than 15 days/month of progestins (usually 10-12 days/month) and 0.25 (0.13 to 0.48 ) for users of regimens with more than 15 days/month (mostly continuously combined exposure). The odds ratios among former users were 0.99 (0.59 to $1.67)$ and $0.42(0.18$ to 0.98$)$ respectively. The odds ratio was 0.29 (0.15 to 0.56$)$ for ever use of regimens with progestins structurally related to progesterone and 0.48 (0.32 to 0.71$)$ for ever use of progestins structurally related to testosterone. Sixty four women had taken both oestrogen alone and oestrogen plus progestin regimens; odds ratios remained similar after these women were excluded. Conjugated oestrogens were used by only 33 $(5.7 \%)$ of women who had taken hormone replacement therapy, and seven of these had also used other types of hormone replacement therapy. The odds ratio for the women who were ever users of conjugated oestrogens only was 0.61 ( 0.23 to 1.59 ).

The risk reduction from hormone replacement therapy diminished with the interval since last use; after five or more years had elapsed only a $25 \%$ overall reduction in risk remained ( $-7 \%$ to $48 \%$ ) (table 3 ). The

Table 3 Effect of time since last use and duration of hormone replacement therapy on risk of hip fracture

\begin{tabular}{|c|c|c|c|c|c|c|}
\hline \multirow[b]{2}{*}{$\begin{array}{l}\text { Use of hormone } \\
\text { replacement therapy }\end{array}$} & \multicolumn{2}{|r|}{ Any } & \multicolumn{2}{|c|}{ Without progestin } & \multicolumn{2}{|c|}{ With progestin } \\
\hline & $\begin{array}{l}\text { No of cases/ } \\
\text { controls }\end{array}$ & $\begin{array}{l}\text { Odds ratio* } \\
(95 \% \mathrm{Cl})\end{array}$ & $\begin{array}{l}\text { No of cases/ } \\
\text { controls }\end{array}$ & $\begin{array}{l}\text { Odds ratio* } \\
(95 \% \mathrm{CI})\end{array}$ & $\begin{array}{l}\text { No of cases/ } \\
\text { controls }\end{array}$ & $\begin{array}{l}\text { Odds ratio* } \\
(95 \% \mathrm{CI})\end{array}$ \\
\hline Never used & $956 / 2073$ & 1.00 (reference) & $956 / 2073$ & 1.00 (reference) & $956 / 2073$ & 1.00 (reference) \\
\hline \multicolumn{7}{|l|}{ Last use $\leqslant 12$ months: } \\
\hline Any use & $47 / 260$ & 0.38 (0.26 to 0.56$)$ & $21 / 70$ & 0.61 (0.35 to 1.04$)$ & $28 / 198$ & 0.28 (0.17 to 0.47$)$ \\
\hline Total use $>5$ years & $14 / 97$ & 0.28 (0.16 to 0.51$)$ & $8 / 36$ & 0.35 (0.15 to 0.82$)$ & $9 / 66$ & 0.24 (0.11 to 0.52$)$ \\
\hline Per year of use & & 0.92 (0.88 to 0.96$)$ & & 0.93 (0.88 to 0.98$)$ & & 0.88 (0.82 to 0.95$)$ \\
\hline \multicolumn{7}{|l|}{ Last use 13-60 months: } \\
\hline Any use & $11 / 45$ & $0.52(0.26$ to 1.04$)$ & 9/23 & 0.82 (0.37 to 1.84$)$ & $7 / 31$ & $0.42(0.17$ to 1.04$)$ \\
\hline Total use $>5$ years & $3 / 18$ & 0.27 (0.08 to 0.94$)$ & $3 / 6$ & 0.65 (0.14 to 3.05 ) & $1 / 12$ & 0.10 (0.01 to 0.87$)$ \\
\hline Per year of use & & 0.91 (0.82 to 1.00$)$ & & 0.97 (0.86 to 1.09$)$ & & 0.78 (0.63 to 0.97$)$ \\
\hline \multicolumn{7}{|l|}{ Last use >60 months: } \\
\hline Any use & $46 / 125$ & 0.75 (0.52 to 1.07$)$ & $38 / 115$ & $0.65(0.44$ to 0.96$)$ & $17 / 38$ & $1.00(0.55$ to 1.82$)$ \\
\hline Total use $>5$ years & $15 / 28$ & 1.07 (0.57 to 2.03 ) & $12 / 22$ & 1.06 (0.52 to 2.19$)$ & $3 / 8$ & 0.74 (0.19 to 2.93$)$ \\
\hline Per year of use & & 0.98 (0.92 to 1.04$)$ & & 0.98 (0.91 to 1.05$)$ & & 0.96 (0.83 to 1.12$)$ \\
\hline
\end{tabular}


Table 4 Odds ratios of hip fracture associated with ever use of hormone replacement therapy by route of administration and dose

\begin{tabular}{|c|c|c|c|c|c|c|}
\hline \multirow{2}{*}{$\begin{array}{l}\text { Use of hormone } \\
\text { replacement } \\
\text { therapy }\end{array}$} & \multicolumn{2}{|c|}{ Any } & \multicolumn{2}{|c|}{ Without progestin } & \multicolumn{2}{|c|}{ With progestin } \\
\hline & $\begin{array}{l}\text { No of cases/ } \\
\text { controls }\end{array}$ & $\begin{array}{c}\text { Odds ratio* } \\
(95 \% \text { CI) }\end{array}$ & $\begin{array}{l}\text { No of cases/ } \\
\text { controls }\end{array}$ & $\begin{array}{c}\text { Odds ratio* } \\
\text { (95\% Cl) }\end{array}$ & $\begin{array}{l}\text { No of cases/ } \\
\text { controls }\end{array}$ & $\begin{array}{c}\text { Odds ratio* } \\
(95 \% \text { Cl) }\end{array}$ \\
\hline Never used & $956 / 2073$ & 1.0 (reference) & $956 / 2073$ & 1.0 (reference) & $956 / 2073$ & 1.0 (reference) \\
\hline \multicolumn{7}{|l|}{ All: } \\
\hline Low dose† & $16 / 40$ & 0.82 (0.45 to 1.51$)$ & $15 / 29$ & 1.02 (0.53 to 1.96$)$ & $1 / 14$ & 0.13 (0.02 to 1.03$)$ \\
\hline High doseł & $80 / 347$ & 0.55 (0.41 to 0.73$)$ & $46 / 145$ & 0.65 (0.46 to 0.94$)$ & $49 / 245$ & 0.47 (0.33 to 0.69$)$ \\
\hline Tablet: & $97 / 389$ & 0.54 (0.41 to 0.71$)$ & $59 / 173$ & 0.63 (0.45 to 0.88$)$ & $55 / 262$ & $0.46(0.32$ to 0.67$)$ \\
\hline Low dose† & $14 / 29$ & 0.93 (0.48 to 1.80$)$ & $13 / 24$ & 1.05 (0.52 to 2.12$)$ & $1 / 7$ & 0.21 (0.02 to 1.77) \\
\hline High doseł & $65 / 300$ & 0.50 (0.36 to 0.68$)$ & $31 / 98$ & 0.61 (0.39 to 0.94$)$ & $49 / 245$ & 0.47 (0.32 to 0.68$)$ \\
\hline Skin patch: & $23 / 94$ & $0.62(0.36$ to 1.06$)$ & $15 / 46$ & 0.73 (0.38 to 1.40$)$ & $12 / 60$ & 0.49 (0.24 to 1.00$)$ \\
\hline Low dose† & $3 / 12$ & 0.47 (0.12 to 1.85$)$ & $3 / 6$ & 0.84 (0.18 to 3.82$)$ & $0 / 7$ & 0 \\
\hline High doseł & $14 / 76$ & $0.52(0.28$ to 0.98$)$ & $7 / 36$ & $0.49(0.21$ to 1.17$)$ & $11 / 51$ & 0.56 (0.27 to 1.18$)$ \\
\hline
\end{tabular}

${ }^{*}$ Adjusted for age (50 to 54,55 to 59,60 to 64,65 to 69,70 to 74,75 to 81 years) and the indication of hormone replacement therapy to prevent osteoporosis (yes/no).

†Equivalent to oestradiol $<2 \mathrm{mg} /$ day, conjugated oestrogens $<0.625 \mathrm{mg} /$ day, ethinyl oestradiol $<10 \mu \mathrm{g} /$ day, transdermal oestradiol $<50 \mu \mathrm{g} /$ day, or any oestradiol given by injection.

$\ddagger$ Equivalent to oestradiol $\geqslant 2 \mathrm{mg} /$ day, conjugated oestrogens $\geqslant 0.625 \mathrm{mg} /$ day, ethinyl oestradiol $\geqslant 10 \mu \mathrm{g} /$ day, transdermal oestradiol $\geqslant 50 \mu \mathrm{g} /$ day, or any oestradiol given by injection.

benefit of long duration of use seemed limited to women who had taken hormone replacement therapy within the past five years. Among these women, those who had a total duration of use longer than five years had a reduction in risk greater than $70 \%$ compared with never users, but no significant reduction in risk remained five years after stopping treatment. In general, within each duration-recency combination, combined treatment provided lower odds ratios than oestrogen alone.

Overall, the protective effect of oestrogens on the risk of hip fracture was dose related. Ever use of a low dose of medium potency oestrogens did not confer a protective effect on hip fracture (table 4). With use of higher doses (equivalent to $\geqslant 2 \mathrm{mg}$ oestradiol or $\geqslant 0.625 \mathrm{mg}$ conjugated oestrogens) oestrogens without progestin reduced the risk of hip fracture, but the addition of progestins was associated with a further reduction in risk. Similar risk reductions were associated with oral administration or skin patches but not with injections. Estimates for injection were imprecise because of small numbers (data not shown). Similar odds ratios were obtained in analyses restricted to those who had used only one route of administration.

Once duration of use was taken into account we found similar protective effects of treatment whenever it was initiated in relation to the time of menopause (table 5). With current use, starting treatment nine or more years after the menopause gave equally strong reduction in risk of hip fracture as an earlier start.

\section{Discussion}

We found that hormone replacement therapy substantially reduced the risk of hip fracture. The reduction was greater with higher oestrogen doses and greater duration of use, but current or recent use of oestrogens was required for substantial protection. Among women who had stopped oestrogens more than five years previously, even long term users had lost most of the benefit. The addition of progestins permitted use of lower doses of oestrogens. Oral and transdermal administration seemed equally effective. Our results also suggest that treatment can start several years after menopause without loss of efficiency in reducing fracture risk.

\section{Comparability}

Previous studies have also found a low relative risk of hip fracture after exposure to exogenous oestrogens, ${ }^{8-14}$ although they had limited statistical power to examine the effects of recency and duration of use, type of administration, and age at starting therapy. Other studies support our finding that the effects of hormone replacement therapy on bone and hip fracture risk dissipate after stopping treatment. The Framingham study found a relative risk of $0.34(95 \%$ confidence interval 0.11 to 1.09 after multivariate adjustment) among current or recent users of oestrogen and of 0.70 ( 0.45 to 1.08$)$ in former users. ${ }^{12}$ Unfortunately, duration of use was only partially considered in this analysis. However, two other investigations that did take into account duration of use also found an apparent loss of benefit. ${ }^{814}$ Studies of bone

Table 5 Effect of time after menopause of starting hormone replacement therapy on risk of hip fracture

\begin{tabular}{|c|c|c|}
\hline $\begin{array}{l}\text { Years after menopause at } \\
\text { time of starting treatment }\end{array}$ & $\begin{array}{l}\text { No of cases/ } \\
\text { controls }\end{array}$ & Odds ratio* $(95 \% \mathrm{Cl})$ \\
\hline Never used & $956 / 2073$ & 1.0 (reference) \\
\hline \multicolumn{3}{|l|}{ All users: } \\
\hline$\leqslant 2$ & $61 / 276$ & 0.53 (0.39 to 0.73$)$ \\
\hline $3-8$ & 19/98 & $0.48(0.28$ to 0.79$)$ \\
\hline$\geqslant 9$ & $29 / 59$ & $0.86(0.52$ to 1.43$)$ \\
\hline \multicolumn{3}{|l|}{ Current users: } \\
\hline$\leqslant 2$ & $16 / 138$ & $0.29(0.16$ to 0.50$)$ \\
\hline $3-8$ & $7 / 56$ & 0.30 (0.13 to 0.69$)$ \\
\hline$\geqslant 9$ & $17 / 43$ & $0.62(0.33$ to 1.18$)$ \\
\hline \multicolumn{3}{|c|}{ Current users, total use $>2$ years: } \\
\hline$\leqslant 2$ & $16 / 107$ & 0.32 (0.18 to 0.58$)$ \\
\hline $3-8$ & $4 / 33$ & 0.28 (0.10 to 0.82$)$ \\
\hline$\geqslant 9$ & $3 / 14$ & 0.26 (0.07 to 1.02$)$ \\
\hline \multicolumn{3}{|l|}{ Last use $\leqslant 5$ years: } \\
\hline$\leqslant 2$ & $28 / 181$ & 0.37 (0.24 to 0.59$)$ \\
\hline $3-8$ & $11 / 77$ & 0.35 (0.18 to 0.69$)$ \\
\hline$\geqslant 9$ & $26 / 52$ & 0.75 (0.43 to 1.32) \\
\hline \multicolumn{3}{|c|}{ Last use $\leqslant 5$ years, total use $>2$ years: } \\
\hline$\leqslant 2$ & $25 / 130$ & $0.40(0.24$ to 0.65$)$ \\
\hline $3-8$ & $6 / 40$ & 0.35 (0.14 to 0.84$)$ \\
\hline$\geqslant 9$ & $5 / 17$ & $0.36(0.12$ to 1.08$)$ \\
\hline
\end{tabular}

${ }^{*}$ Adjusted for age (50 to 54,55 to 59,60 to 64,65 to 69,70 to 74,75 to 81 years) and the indication of hormone replacement therapy to prevent osteoporosis (yes/no). 
density are also consistent with a waning benefit after stopping hormone replacement therapy. ${ }^{15} 16$

Evidence regarding the age at starting treatment is conflicting. A significant protection from hip fracture among women who began hormone replacement therapy within five years after menopause was found in the study of osteoporotic fractures but not among women who began later. ${ }^{8}$ However, in a recent cross sectional study of bone density, nearly equal bone conserving benefit was seen for oestrogen therapy begun before age 60 years or after if the treatment was continued. ${ }^{15}$

We have found no other comparison of the effects of oestrogen alone and oestrogen plus progestin on risk of hip fracture. However, consistent with our findings, the study of osteoporotic fractures reported that compared with never users the relative risk for all fractures was 0.69 (0.56 to 0.86) among current users of hormone replacement therapy without progestin and 0.51 (0.33 to 0.78) among users of combined treatment. ${ }^{8}$ These data and ours clearly suggest that progestins have a bone sparing effect and are supported by studies which show that progestins stimulate osteoblasts and promote bone formation. ${ }^{17} 18$ Moreover, the addition of progestins to oestrogen seems to give a better effect on bone density than oestrogen alone. ${ }^{19-21}$

We were able to evaluate dose and type of administration on the risk of hip fracture. Skin patches and oral treatment seemed to confer equally strong risk reductions, but oestrogen administrated by injection was not associated with substantial risk reduction. Transdermal oestradiol has been reported to be effective in preventing further vertebral bone loss and fractures in women with established osteoporosis. ${ }^{22}$

We found that a low dose of oestrogen without progestins (for example $1 \mathrm{mg}$ of oestradiol or $0.325 \mathrm{mg}$ conjugated oestrogens) was not associated with a reduction in the risk of hip fracture. This finding supports the contention that the minimum effective dose of oestrogen without progestin to prevent postmenopausal bone loss in most individuals is $2 \mathrm{mg}$ oestradiol, $0.625 \mathrm{mg}$ conjugated oestrogens daily, or equivalent. ${ }^{23} 24$

The mechanism underlying the effect of oestrogen treatment on bone is not clearly understood but is thought to involve inhibition of osteoclasts, ${ }^{5}{ }^{25}$ which slows bone turnover and improves the balance between bone formation and resorption. ${ }^{5}$ Oestrogen also improves calcium retention through increased intestinal calcium absorption and renal calcium reabsorption. ${ }^{26}$ Oestrogen may also influence other factors related to fracture risk-for example, extraskeletal effects such as improved balance. ${ }^{27} 28$

\section{Strengths and weaknesses}

The strengths of our study are the large size, the population based design, and the high response rate. The precision and validity of our study was augmented by the thorough ascertainment of exposure, cross checking of different registers for assessing fractures, and verification of the diagnosis through hospital records. We did not include subjects with known senility, alcoholism, and psychosis, mainly because of the likelihood of inadequate recollection. However, the effect of our exclusions on the overall relative risk is uncertain.
- Hormone replacement therapy should be continued for long periods for optimal protection of hip fracture

- No overall substantial hip fracture protection remains after five years without hormone replacement therapy

- Therapy can be initiated several years after menopause without loss of fracture protection

- Oral or transdermal therapy are equally effective in reducing the risk of hip fracture

- The addition of progestins permits lower doses of oestrogens

The principal potential limitations of an observational study such as ours are possible confounding and measurement error as well as response biases. A further issue, even in our comparatively large study, is low statistical power in some subgroups. There was little indication in our data that known risk factors for hip fracture confounded the effects of hormone replacement therapy, but unknown factors could have distorted our findings. A particular concern is that women who take hormone replacement therapy may have a lower risk of fracture for reasons other than the hormone replacement therapy.

Our case-control study indicates that to prevent hip fracture hormone replacement therapy may be started several years after menopause but should be continued for long periods. Oral or transdermal therapy seem equally effective, and the addition of progestins permits lower doses of oestrogens.

The Swedish Hip Fracture Study Group comprised Akke Alberts, John A Baron, Thomas Dolk, Bahman Y Farahmand, Olof Johnell, Lena Lindén, Sverker Ljunghall, Karl Michaëlsson, Per-Gunnar Persson, K-G Thorngren, Mats Thorslund, Carl Zetterberg, and Lena Zidén.

Contributors: $\mathrm{KM}$ is the guarantor of the study. KM, JAB, P-GP, and SL designed the study. KM coordinated the project and the writing of the article and analysed the data with BYF and JAB. KM, JAB, OJ, CM, P-GP, IP, SL, Akke Alberts, Karl-Göran Thorngren, and Mats Thorslund participated in the design of the questionnaire. Data collection was organised by KM supported by IP and SL and facilitated by CM, OJ, Akke Alberts, Thomas Dolk, Karl-Göran Thorngren, Carl Zetterberg, and Lena Zidén. Lena Lindén was the interviewer and administrator with help from Birgit Wellander. Hans-Olov Adami provided epidemiological advice. All authors participated in writing the manuscript.

Funding: Swedish Council for Social Research (project 93-0029) and US National Institutes of Health (NR 1 RO 1 CA58427).

Conflict of interest: None.

1 Nilas L, Christiansen C. Bone mass and its relationship to age and the menopause. J Clin Endocrinol Metab 1987;65:697-702.

2 Riggs BL, Melton III LJ. Involutional osteoporosis. N Engl J Med 1986;314:1676-86.

3 Melton III LJ, Cummings SR. Heterogeneity of age-related fractures: implications for epidemiology. Bone Miner 1987;2:321-31.

Kanis JA, Pitt FA. Epidemiology of osteoporosis. Bone 1992;13:S7-15.

5 Hillard TC, Stevenson JC. Role of oestrogen in the development of osteoporosis. Calcif Tissue Int 1991;49:55-9.

6 Christiansen C, Lindsay R. Estrogens, bone loss and preservation. Osteoporos Int 1990;1:7-13.

7 Grady D, Rubin SM, Petitti DB, Fox CS, Black D, Ettinger B, et al. Hormone therapy to prevent disease and prolong life in postmenopausal women. Ann Intern Med 1992;117:1016-37.

8 Cauley JA, Seeley DG, Ensrud K, Ettinger B, Black D, Cummings SR. Estrogen replacement therapy and fractures in older women. Study of Osteoporotic Fractures Research Group. Ann Intern Med 1995;122:9-16. 
9 Michaëlsson K, Holmberg L, Mallmin H, Sörensen S, Wolk A, Bergström R. Diet and hip fracture risk: results from a case-control study. Int J Epidemiol 1995;24:771-82.

10 Naessén T, Persson I, Adami H-O, Bergström R, Bergkvist L. Hormone replacement therapy and the risk for first hip fracture. Ann Intern Med 1990;113:95-103.

11 Maxim P, Ettinger B, Spitalny GM. Fracture protection provided by longterm estrogen treatment. Osteoporos Int 1995;5:23-9.

12 Kiel DP, Felson DT, Anderson JJ, Wilson PWF, Moskowitz MA. Hip fracture and the use of estrogens in postmenopausal women. $N$ Engl J Med 1987;317:1169-74

13 Kanis JA, Johnell O, Gullberg B, Allander E, Dilsen G, Gennari C, et al. Evidence for efficacy of drugs affecting bone metabolism in preventing hip fracture. BMJ 1992;305:1124-8.

14 Weiss NS, Ure CL, Ballard JH, Williams AR, Daling JR. Decreased risk of fractures of the hip and lower forearm with postmenopausal use of estrogen. N Engl J Med 1980;303:1195-8.

15 Schneider DL, Barrett-Connor EL, Morton DJ. Timing of postmenopausal estrogen for optimal bone mineral density. The rancho bernardo study. JAMA 1997;277:543-7.

16 Felson DT, Zhang Y, Hannan MT, Kiel DP, Wilson PWF, Anderson, JJ. The effect of postmenopausal estrogen therapy on bone density in elderly women. N Engl J Med 1993;329:1141-6.

17 Christiansen C, Riis BJ, Nilas L, Rodbro P, Deftos L. Uncoupling of bone formation and resorption by combined oestrogen and progestagen therapy in postmenopausal osteoporosis. Lancet 1985;i:800-1.

18 Prior JC. Progesterone as a bone-trophic hormone. Endocr Rev 1990;11:386-98
19 Speroff L, Rowan J, Symons J, Genant H, Wilborn W. The comparative effect on bone density, endometrium, and lipids of continuous hormone as replacement therapy (CHART study). JAMA 1996;276:1397-403.

20 Gallagher JC, Kable WT, Goldgar D. Effect of progestin therapy on cortical and trabecular bone: comparison with estrogen. Am J Med 1991;90:171-8

21 Effects of hormone therapy on bone mineral density. Results from the postmenopausal estrogen/progestin interventions (PEPI) trial. JAMA 1996;276:1389-96

22 Lufkin EG, Wahner HW, O'Fallon WM, Hodgson SF, Kotowicz MA, Lane AW, et al. Treatment of postmenopausal osteoporosis with transdermal estrogen. Ann Intern Med 1992;117:1-9.

23 Lindsay R, Hart DM, Clark DM. The minimum effective dose of estrogen for prevention of postmenopausal bone loss. Obstet Gynecol 1984;63:759-

24 Horsman A, Jones M, Francis R, Nordin C. The effect of estrogen dose on postmenopausal bone loss. N Engl J Med 1983;309:1405-7.

25 Rizzoli R, Bonjour J-P. Hormones and bones. Lancet 1997;349(suppl 1):20-6

26 Heaney RP. Calcium in the prevention and treatment of osteoporosis. $J$ Intern Med 1992;231:169-80.

27 Hammar L, Lindgren R, Berg GE, Moller CG, Niklasson MK. Effects of hormonal replacement therapy on the postural balance among postmenopausal women. Obstet Gynecol 1996;88:955-60.

28 Naessen T, Lindmark B, Larsen HC. Better postural balance in elderly women receiving estrogens. Am J Obstet Gynecol 1997;177:412-6.

(Accepted 12 February 1998)

\title{
The 1998 European Resuscitation Council guidelines for adult advanced life support
}

\author{
Advanced Life Support Working Group of the European Resuscitation Council
}

The publication of guidelines for advanced life support by the European Resuscitation Council in 1992 was a landmark in international cooperation and coordination. ${ }^{1}$ Previously, individual countries or groups had produced guidelines, ${ }^{2}$ but for the first time an international group of experts produced consensus views based on the best available information. Since 1992 even wider international collaboration and support has occurred. In particular, the establishment of the International Liaison Committee on Resuscitation has facilitated global cooperation and discussion between representatives from North America, Europe, Southern Africa, Australia, and most recently Latin America. The advisory statement produced in 1997 by the committee forms the basis for these guidelines. ${ }^{3}$

The 1992 guidelines by the European Resuscitation Council indicated that review would occur on a regular basis. Change is not advocated for its own sake and is not warranted without convincing scientific or educational reasons. Education and its organisation is a process with a long latency, and it can be confusing and distracting for trainers and trainees if the message lacks consistency.

The Advanced Life Support Working Group of the European Resuscitation Council recognised that the previous guidelines necessitated a level of rhythm recognition, interpretation, and subsequent decision making that some users found difficult. While automated external defibrillators ease some of these problems, the 1992 guidelines were not specifically designed for these devices. These new guidelines are applicable to manual and automated external defibrillators. Decision making has been reduced to a minimum whenever possible. This increases clarity, while still allowing people with specialist knowledge to apply their expertise
Changes in guidelines are only the first step in the process of care. Their implementation necessitates considerable effort. Training materials and methods may require modification, information must be disseminated, and, perhaps most importantly, evaluation of efficacy is needed. For these purposes, reporting and publication of out of hospital and in-hospital cardiac arrest events using the Utstein templates ${ }^{45}$ is strongly advised to provide objective assessment of outcome.

The limitations of guidelines must be recognised. As always in the practice of medicine, words and flow charts must be interpreted with common sense and an appreciation of their intent. While much is known about the theory and practice of resuscitation, in many areas our ignorance is profound. Resuscitation practice remains as much an art as a science. Furthermore, the interpretation of guidelines may differ according to the environment in which they are used. We acknowledge that individual resuscitation councils may wish to customise the details while accepting that the guiding principles are universal. Any such changes must be approved by the European Resuscitation Council if they are to be regarded by this organisation as representing its official guidelines.

\section{Precursors to cardiac arrest}

In the so called industrialised world the commonest cause of adult sudden cardiac death is ischaemic heart disease ${ }^{6-9}$ Prevention of cardiac arrest is to be greatly preferred to post hoc treatment. The guidelines on the management of peri-arrest arrhythmias produced by the European Resuscitation Council in 1994 and updated in 1996 and 1998 are concerned with treating arrhythmias that may lead to the development and recurrence of cardiac arrest in critical situations. ${ }^{10}$
Editorial by Nolan

Members of the working group are listed at the end of the article

BMJ 1998;316:1863-9

These guidelines have been published in Resuscitation, the official journal of the European Resuscitation Council (Resuscitation 1998;37:81-90) 